\title{
Affective Aesthetics
}

\author{
Robert Lumsden \\ National Institute of Education, Singapore; \\ National University of Singapore, Singapore
}

We merely make a temporary invention which covers that part of the world accessible to us at the moment.

Jacob Bronowski, The Origins of Knowledge and Imagination

\begin{abstract}
The paper moves from a consideration of poetic meaning as a somatic, whole body instantiation of imagined verbal structures to an investigation of aesthetic experience in general as a selective excitation of neurologically encoded spectra of possible responses grounded in empathy. It proposes that a particular type of critical enquiry involving a continual entertainment of the full range of the multiplicity of explanations suggested by any aesthetically framed phenomenal presentation can and ought to ensue from such a consideration, and that such a critical (re)orientation might serve as a bridge between uninspected predispositions to feel and judge in fixed ways and the kind of apparently self-evident, haptic, experience which characterizes aesthetic responses. In the process, certain assumptions concerning empirical enquiry in general, and such forms of enquiry as adopted in cognitive psychology, are scrutinized. The position outlined has some affinity with the constructivist model of knowledge accumulation proposed by Ernst Glasenfeld, with the difference that the pre-inscribed dispositions which issue as normalized judgments are seen as empathy based, rather than as effect describable by conceptual-semantic algorithms, as they appear to be in the constructivist model.
\end{abstract}

Keywords: aesthetic responses, empathy, objectivity, critical perspective

\section{Introductory}

Beginning with a consideration of poetic meaning as a somatic response, this paper investigates aesthetic experience in general as a selective excitation of neurologically encoded spectra of possible responses grounded in empathy. It moves from this speculative description to the mapping of a critical approach made possible in accounts of self-reflection taken as an aspect of the psychology of perception.

Intent is treated here as distinct from such "perceptual sets" as Husserl's "natural attitude" of "already pre-given and generally un-reflected intentional background"1. Rather, it is taken as a displacement from the

Robert Lumsden, Ph.D., independent scholar, formerly senior research fellow, National Institute of Education; senior lecturer, National University of Singapore.

${ }^{1}$ Husserl's "natural attitude" understood as generally unreflected intentional background is problematic in its presentation of immediacy (See in this connection Wolfgang Iser's description of Husserl's phenomenology as essentially an argument for the viability of unmediated experience: "Phenomenology was conceived by Edmund Husserl as a form of scientific research. His basic operation consisted in a 'transcendental reduction' of phenomena in order to understand how the latter is given in an unmediated perception to consciousness". Iser, 14 (My emphasis)). A solution to the dilemma of how immediacy can be reported without being changed is suggested by advocates of Husserl's system in the process of retention and protention, by means of which the moment of perception might be reconstituted in its original form. But to recollect a moment of experience is necessarily to place that moment in the past, however that process is subdivided, and the subdivision is named. To account for such a recollection in reporting it and theorizing about it is inevitably to shift the moment even further into a pastness of metanarration. Of those who are inclined to accept Husserl's categories of "retention" and "protention" as solutions to the methodological impossibility of re-presenting an original moment as it was from a point successive to it, it should be asked: How do "retention" and "protention", which are supposedly beyond chronology, differ from remembering, which is not? 
regard given an aesthetic response to a perceiver's sense of that response in critical accounts of it as these are retrieved from pre-established matrices. This "map" is a series of claims inviting investigation more than a blueprint, especially in the matter of the nature of the principle of coordination which aligns certain "higher" brain functions (the mirror neurons and the ventromedial prefrontal cortex, in particular) with some of the more "primitive” or "deep brain” functions (the amygdala, hippocampus, caudate nucleus and the peripheral nervous system) $)^{2}$.

Bechara, Damasio, and Damasio (2000) situated this principle of coordination of empathetic response, described here in terms of a spectrum or matrix, in the ventromedial prefrontal cortex, and while this is plausible in terms of current best knowledge, from the present point of view, it leaves open the question of the nature of the instruction, or disposition to ordering, which prompts the ventromedial prefrontal cortex itself, an iteration in microcosm of the mystery of the origination of all forms, material or ideational. This matter will be addressed in the section below subtitled "The mirror neuron system, ventromedial prefrontal cortex and the consensual spectrum”.

\section{Poetry, Somatic Meaning, and Objectivity}

When the 18th century scholar poet A. E. Houseman proposed the bristling of his beard as the measure of poetic excellence - the tougher the shave, the better the poem—-he annulled thought in the celebration of a physical response ${ }^{3}$.

Such a bodily referenced conception of aesthetic responses has been attractive not only to poets, such as Houseman, Gerard Manley Hopkins, and Emily Dickinson, but subsequently to near contemporaries as stylistically diverse as Louis Zukovsky, Basil Bunting, and Charles Olsen, on through to various performance poets (Bob Cobbings and Edwin Morgan), and in the work of some of the language poets who at times draw upon a type of visceral-diaphragmatic parsing of meaning reminiscent of Anglo-Saxon onomatopoeic-alliterative verse $^{4}$.

\footnotetext{
${ }^{2}$ Antonio Damasio: “The orbitofrontal cortex sends and receives information from the amygdala, hippocampus, and caudate nucleus”. In Antoine Bechara, Hanna Damasio, and Antonio R. Damasio (Eds.) (2000), The mysterious Orbitofrontal cortex. Oxford Journals, 10(3) 295-307. Retrieved May 23, 2011, from http://cercor.oxfordjournals.org/ content/10/3/205.full

See Jean Decety, To What Extent Is the Experience of Empathy Mediated By Shared Neural Circuits? Retrieved from May 27, 2011, http://www.chicago.academia.edu/JeanDecety/Papers/320639/To-What-Extent-is-the-Exp

"Conclusion: Further research in affective neuroscience needs to refine conceptually what processes are encompassed in the experimental designs and at what level (e.g., implicit vs. explicit). This is critical, because empathy belongs to self-conscious emotions which rely on complicated and distributed brain networks including the posterior superior temporal sulcus, amygdala, insula, medial and prefrontal cortices” (My emphasis). A crucial part of t his conceptual refinement, I suggest, should be description of the critical processes involved in representing it, especially as these trade with notions of objectivity.

3 "Experience has taught me, when I am shaving of a morning, to keep watch over my thoughts, because, if a line of poetry strays into my memory, my skin bristles so that the razor ceases to act. The seat of this sensation is the pit of the stomach". The Leslie Stephen Lecture, Cambridge University, May 9, 1933. We may think of this as the "shiver" factor in acknowledgement of Frank Kermode's article on that element in the poetry of T. S. Eliot and Tennyson, among others, in London Review of Books, Vol. 32, No. 9, May 13, 2010, pp. 13-16.

Compare with Emily Dickinson: "If I read a book and it makes my whole body so cold no fire can warm me, I know that is poetry. If I feel physically as if the top of my head were taken off, I know that is poetry. These are the only ways I know it. Is there any other way?” (Selected letters).

4 The onomatopoeic element, especially. Basil Bunting and Louis Zukofsky called for a renewed emphasis on declamatory poetry, and Bunting in particular considered that the poem on the page, after the fashion of a musical score, was not fully intelligible until spoken or sounded. From this perspective, performance poetry is best considered, not as a twentieth century consort of post modernism, but as originating in the memorized epics of pre-literate societies, vestiges of which remain in some Balkan countries and the Welsh Eisteddfod. See Ted Hughes' essay on Vasko Popa and his poem cycle on St. Sava of the Wolves in Winter Pollen: Occasional Prose in this connection.
} 
From the point of view of those who prefer to locate aesthetic significance in conceptual process, such soma subjectivists, as we might call them, miss those nuances which were available to cognitive thinking ${ }^{5}$. But there is also no lack of poet scholars or scholar poets among this group-sometimes these are the same poets in a different mood, who, while honoring the affective element in the making and reception of poetry, do continue to seek objective bases for aesthetic judgment, either in the sound structures of language-Robert Frost's sentence sounds, for instance, or in the exact particulars of rhythm—Ezra Pound's absolute rhythm, or in arrangements supposed to inhere both in the text and an ideal reader's perception of the text simultaneously- $\mathrm{T}$. S. Eliot's objective correlative may be regarded as an attempt of this sort ${ }^{6}$.

Such aspiration to objectivity reaches a particular peak with the American New Critics of the forties and fifties of the previous century and literary critics of the Chicago school in their elaboration of critique around a few features of style made fundamental by fiat. Tension, ambiguity, paradox and the rest from the perspective proposed here were best considered, not as markers of textually encoded facts, as they were in the parlance of those schools, but as the names of aspirations to objectivity apparently confirmed in an accumulation of detail. It is not verbal icons with which we have to deal in such accounts, but images of objectivity as desiderata projected into texts.

In general, a problem for any objectivism made plausible by elaboration is the tendency of its proponents to assume that key principles have been demonstrated by a listing of instances. This tends to obscure weaknesses in the premises on which those instances are founded ${ }^{7}$.

The author has taken the New Critics as a case in point, but a similar observation can be made, to cite two other instances only, of Wolfgang Iser's reader response theory, and Michel Riffaterre's concept of the hypogram as a given element in the poetic text. In their descriptions of reading, and against the expectation raised by the name of the movement to which both theorists are thought to belong, an idea of adequate interpretation is controlled by textual features whose existence is supposed to be independent of a reader's construal, or even his/her noticing, of them ${ }^{8}$.

But there are several indications that objectivity as word and concept is after all worth spending the time on it, at least as far as literary interpretation is concerned. For example, the apparent universality of the response of readers to similar stories across cultures of the sort considered in the work of Propp (1958) and Greimas (1983), and especially the latter's principle of isotopy redefined (as “direction”) by Umberto Eco (1980). A second indication is that "objectivity" is not merely the name of a type of "tricked up" version of

\footnotetext{
${ }^{5}$ Taste, for those proposing an immediacy distinct from a reflection which is distanced cognitively from it, is often body-referenced, and aesthetic judgement remains near to the physical even after it has been theorized. This nearness is sometimes declared trenchantly in surprising quarters-in Pierre Bourdieu's description of "poor taste" as another's internalized cognitive structures, for instance, and his view that disapproving judgement is naturally expressed as "disgust provoked by horror or visceral intolerance”. (Distinction, 56) (My emphasis).

6 "The only way of expressing emotion in the form of art is by finding an 'objective correlative'; in other words, a set of objects, a situation, a chain of events which shall be the formula of that particular emotion; such that when the external facts, which must terminate in sensory experience, are given, the emotion is immediately evoked”. T. S. Eliot, Hamlet and his problems, The Sacred Wood, 1922.

Frost and Pound must also assume a catholicity of correct hearing, itself presumptive of a grounding in given textual features, to support their discriminations and recommendations. In the case of Frost, a normative intonation pattern is assumed to be inscribed in the poem by its diction at sentence level; in Pound's, a rhythmic absolute encoded across the stanza, the line, and even within the phrase, is proposed as an equation for the feeling state of the writer at the time of composition.

${ }^{7}$ An associated difficulty is the kind of covert "liberal" authoritarianism which is common (in several senses of the world) in academic life, not least in the teaching of literature.

${ }^{8}$ There is an increased inclination to displace interpretative authority from the reader to the text from the publication of Iser's The Implied Reader, which appeared in English in 1978, to The Act of Reading, published two years later.
} 
subjectivity, one which will provide the focal point of the rest of this paper, concerns some connections between aesthetic responses and the activity of certain brain regions.

\section{Body Spectra}

Taking seriously the suggestion gathered from the soma-subjectivist poets that autonomic body responses provide a bridge between out-there experiences and their inner states, the authors will look initially for an illustration of this pattern of aesthetic judgments in the physical process of seeing.

It is known that the light spectrum extends beyond what we can see of it unaided, but the reality quotient freely accorded unaided seeing is not so easily ascribed to those parts of the spectrum that we acknowledge with the aid of instruments. Because gamma rays exist for us essentially as an idea, they do not have the reality of light reflected from a swimming pool in a David Hockney's painting. Though the light rendered in the painting, no less than the gamma rays whose existence is signified by machine, comes to the observer twice removed from the represented scene, it seems incontrovertibly more real, because it is conveyed by neurological exchanges which are not interrupted by a reasoning process. The "story" told by the painting of light reflected from the surface of a Californian swimming pool is inherently more persuasive than an account generated by measurement of a part of the light spectrum not visible to the naked eye.

In the quality of such feeling, as it is when naturally given to the primary sense, the soma subjectivist poets have supported. As far as critical enquiry is concerned, in noticing such difference in the way "reality" signifies, as between an apparently unmediated and a mediated experience, we may observe ourselves by a switch of critical perspective becoming aware of our submission to an otherwise invisible disposition, realizing that objective is no more, but not less, than a designation for that experience. Paying due and consistent attention to this fact that seeing objectively can justly be defined as an unmediated submission to an uninspected automaticity resets critical mind radically.

This spectrum of the immediately received and unreflected upon both permits and constrains invention. We are free to invent a new name for a tint made from a mixing of primary colors, but we cannot invent a new primary color. We can mix anew from given fundamentals; can create a perceptual occasion which seems certain, because it seems to stand outside the process of which it is a part. Or, we might contrive objects and events which initially appear as improbable as unicorns but become no less real than a recollection of one's first and only sighting of a bull moose once both experiences_-unicorn and bull moose-are either submitted to sufficiently to forgo critical perspective in favor of living a waking dream of fantastical things taken unquestioningly as realities—-the "sleepwalker's" life vision—or seen from a critical perspective as instances of a similar neurological process allotted their reality-quotients by sustained acts of preferential judgment ${ }^{9}$.

\footnotetext{
${ }^{9}$ (1) "The imagination then, I consider either as primary, or secondary. The primary imagination I hold to be the living Power and prime agent of all human perception, and as a repetition in the finite mind of the eternal act of creation in the infinite I AM. The secondary imagination I consider as an echo of the former, co-existing with the conscious will, yet still as identical with the primary in the kind of its agency, and differing only in degree, and in the mode of operation. It dissolves, diffuses, dissipates, in order to recreate; or where this process is rendered impossible, yet still at all events it struggles to idealise and unify. It is essentially vital, even as all objects (as objects) are essentially fixed and dead”.

Fancy, on the contrary, has no other counters to play with, but fixities and definite. The fancy is indeed no other than a mode of memory emancipated from the order of time and space; while it is blended with, and modified by that empirical phenomenon of the will, which we express by the word "choice". But equally with the ordinary memory, the fancy must receive all its materials ready made from the law of association”. Samuel Taylor Coleridge, Biographia Literaria, Bk X111.

In Coleridge's definition, the Secondary Imagination's commerce with the will, being in close conjunction with a "struggle to
} 
A connection between imagination and versions of divinity is not infrequently presumed in the history of literary thought and philosophy, especially where the two modes of address towards the world overlap—Plato, certain of the British idealists, Coleridge — but this is not a necessary connection, nor is it the most satisfactory, or the most comfortable of associations with what is felt to be cognitively extraordinary in the merely human. Several questions immediately arise concerning this association. If the imagination is divine, why do its productions often offend the aspiration to live nobly? From whence, the appetite for vampire themes in the cinema and the enthusiasm for forensic police procedurals, so pervasive they appear at times to be a part of a re-defining of popular culture courtesy of Leopold von Sacher-Masoch and the Marquis de Sade? If the

unify", can hardly be conceived as other than a matter of choice, though Coleridge tries to shift its operations from will-evidenced-in-choice with his presentation of both the Primary Imagination and Secondary Imagination as, "essentially", conduits of divinely supplied idealisations. But the prospect of will struggling to idealise surely supersedes the image of Imagination freely receiving an imprint of the Divine in the form of ideas. Rather, it seems inevitable that the Secondary Imagination, as is Fancy, must be dependent upon sense impressions gathered from the object world. Will, struggling, entails a will struggling between two or more options. Are we to suppose this struggle taking place between competing ideas offered by Divinity? That would present a disturbing picture of a god of dualisms, if not God divided, which it is clear to Coleridge, with his emphasis on the unifying character of the imagination, does not want. The question then arises: with what elements is this process of choice involved, if not with competing ideas or invitations to idealisation issuing from God? Unless we are to submit unquestioningly to Coleridge's image of the imagination as, like God, ex nihilo creative, we are bound to suppose that this struggle to idealize among choices must depend, as it does Fancy, upon ideas assembled in memory drawn originally from sense impressions. If not those, then what? In a manner of speaking, the "fixities and definite” Fancy makes from sense impressions are passed back and up to the Primary Imagination via the Secondary Imagination as a kind of taint or infection. Negative evidence of this link, or taint, can be found by readers of a certain disposition in the examples of poets who shift attention too far from material, world-grounded, metaphor, either consciously, in accordance with their poesis, or accidentally. When inspiration ('inspiration') is “de-concretized”, or "God-shifted”, after the manner of Mallarmé or Swinburne, Swedenbourg or Coleridge himself, the creative element is often so attenuated that little more purchase on the reader remains than a linguistic shadow moving across mind, the spectre of a half-remembered substantiality "palely loitering". Insofar as telling a successful figure of speech-metaphor, especially, from one which is less successful depends on an assumption of the existence of a grounding principle, erasure of the boundary between imagination and fancy has profound consequences for literary judgements.

(2) Hume's objectivism

"Let all the different shades of that color (a missing shade of blue never experienced by the subject of whom Hume speaks) except that single one, be placed before him, descending gradually from the deepest to the lightest; tis plain, that he will perceive a blank, where that shade is wanting, and will be sensible, that there is a greater distance in that place betwixt the contiguous colours, than in any other. Now I ask, whether "tis possible for him, from his own imagination, to supply this deficiency, and raise up to himself the idea of that particular shade, tho", it had never been conveyed to him by his senses? I believe there are few but will be of the opinion that he can; and this may serve as a proof, that the simple ideas are not always derived from the correspondent impressions; tho' the instance is so particular and singular, that 'tis scarce worth our observing, and does not merit that for it alone we should alter our general maxim””. L. A. Selby-Bigge (Ed.), Treatise of Human Nature, 2nd ed., revised by P. H. Nidditch, Oxford: Clarendon Press, 1975, p. 6.

It is by no means plain to this reader that a blank would be perceived in Hume's sequence of colors. Hume seems to be imposing a normative and objective notion of the color spectrum, conceived as available to all perceivers, on the subjective experience of color perception of the individual person of his example, and to locate a sense of something missing by measuring that subject's against a proposed common experience. But this individual's experience will seem complete in itself to that individual, as she or he experiences it. Further, referring again to Coleridge, it seems that not only is it possible imaginatively to "produce" a new "shade" not previously experienced by the senses, but that we continually do so; and it seems to be the case - contra Coleridge now - that Fancy can do the job as well as the Secondary Imagination. Seen in this light, "works of Fancy (merely)" and "works of the imagination (truly)" are nothing other than significations marking a preference for one instance over another.

Compare Thomas Metzinger's account of perception: "You perceive a certain object and in the very process of perception the subjective sensation of blueness is formed: the book appears to be blue... Such isolated phenomenal properties are the simplest examples of the subjective, experiential character of consciousness... Among English-speaking philosophers, the mental states associated with such simple phenomenal properties are sometimes identified with the concept of raw feeling”. Thomas Metzinger (Ed.), Conscious Experience. Schoningh. Imprint Academic, 1995, p. 9. 
imagination is God-affianced, why are such productions felt to be so enjoyable by so many?

Felt is the operative word here. Colin Wilson ${ }^{10}$ pointed to the existence of a tradition of intelligence of the highest sort which is experienced only in and through flesh abjuring the hegemony of reason, a type of lived philosophy shown in Wilson's view by a handful in any age, and in our era perhaps in the life of the dancer Vaslav Nijinsky wrote particularly, "I am insight through flesh, not through either mind or feeling”. This comment fits nicely into the perspective of a schism between the group that the author has been calling soma subjectivists, and that majority which continues to hold, as a practical matter (possibly unconsciously), to the idea that matches between the observation of a thing and the real world substantiation of which the object seems capable, perhaps with the imagination's help, but in any case waiting prospectively at some future place of convergence of speculation with observation, however distant. Nijinsky's use of the word "feeling" in the line just quoted seems at first sight not to fit well with this view, but it could be understood to refer to the kind of troubled projection of self-interest which belongs to the sphere of mind, since elsewhere in the diary he speaks of what is clearly a higher feeling state as being coterminous with wisdom, "I am God in a body. Everyone has this feeling, but no one uses it"11. And Nijinsky's vision is by no means a dualist. He does not rescind reason absolutely; he redefines it so that it operates as encompassing signifier of the enhanced feeling-state, he venerates: "Every man is a reasonable being. I do not want unreasonable beings, and therefore I want everyone to be in a trance of feeling"12.

The link between this "trance of feeling" and the body-referencing of such soma-subjectivists as Houseman and Dickinson is perhaps best seen in William Blake's absolute identification of body and spirit, and feeling as a singularity. Blake makes this case by as deft a piece of type switching as one might find packed into a single sentence when he writes, "Man has no body distinct from his soul, for that body is a portion of the soul discerned by the five senses", where he first seems to dismiss the body as relatively inconsiderable before instating it in a greater glory, as "soul", only to switch a second time, and confer the glory attending that word upon the senses. With two swift strokes, two turns of those meanings usually accorded "body" and "soul", intelligence at its highest is glorified sensuously. The compression of meaning here, the overturning of meanings and the transposing of them to end beyond their normal usage, bear the imprint of genius.

More to the present point, such a perception could hardly have been produced by one who had not embodied it already in the life. Such utterances are themselves the best possible demonstration, beyond mere empirical observation, of the continuous two-way commerce between body and feeling, the continual heightened feeling as body and soul bounded, but not circumvented, by reason, clearly a fundamental truth for Blake. Here he is, again, making this position as explicit, at greater length:

Man has no body distinct from his soul, for what is called body, and portion of the soul discerned by the five senses:

\footnotetext{
${ }^{10}$ Wilson, The Outsider, pp. 95-112. Though intellect in Wilson's view must be more fully integrated into the life than it seems to have been for Nijinsky, I take the dancer here, as does Wilson, as a useful example of a necessary break with the tendency to presumptuousness of intellect left unchecked. Although: "As far as the Outsider is concerned, it is more important to have a powerful intellect than a highly developed capacity to feel” (Wilson, p. 114.), making a breach in reason's hegemony is necessary if intellect is to achieve that higher state available to it, and the emphasis on the feeling body of a Nijinsky, as Wilson suggests, offers that service.

${ }_{11}$ Nijinsky, 49, quoted in Wilson, 106.

12 Nijinsky, 49, quoted in Wilson, 106.
} 
Energy is the only life, and is from body, and reason is the bound or outward circumference of energy ${ }^{13}$.

As far as the imagination is concerned, it can be understood in these somatic and neurological terms as a variation or merging of elements within the given parameters of the credible which seems objective insofar as it is drawn from a place near to the centre of what we are primed to consider normative because of a prior established familiarity. Fancy, in this perspective, would be defined as the speculative invention of an apparently and previously un-experienced element and its establishment rhetorically as the first order experience, an objectivism which we take as objective, that is to say. Such essentially fanciful objectifications, given the brain's plasticity once it has been lifted, or jolted into a new paradigm, might subsequently be shifted nearer to imagination's centre which might, in turn, move nearer to what we take to be reality proper, the thing in itself, that epitome of preference ${ }^{14}$.

A second fundamental body process which to a degree parallels that of unaided vision is the beating of the heart, which in an earlier, now out of favor, "neurogenic" explanation, is prompted by an electrical signal sent to the heart muscle from the sinoatrial node in the right atrium which can be tracked back to the medulla oblongata in the brain stem. In a newer and currently favored aetiology, the "myogenic" explanation, the impulse of the heart to beat is prompted by a disposition of the tissue of the heart muscle itself at cellular level (with what degree of consciousness \{at cellular, rather than organ level\} we might well enquire).

Whether most persuasively located in part of the limbic system of the brain, or in heart muscle tissue, attempts to trace the genesis of the heartbeat, in common with the other descriptions offered here, can offer no more than a closing upon explanation inviting further hypothesis, not completion. Whatever explanation is selected, a place will be reached where it becomes plain that qualification is required of a case which to that point seems secured by the available data if the hypothesis which has been serving as a working model is to remain plausible. In the case of the beating of the heart and of aesthetic response, as in descriptions of the origin of matter itself, at the far end of this spectrum, precisely at the place where assurance of speculation supported by observation begins to fade to invisibility, invariably there will be a necessity for re-conceptualizing "things as they are". In short, as Bronowski suggested in the epigraph at the head of this paper, things as they appeared are really(sic) only ever things made suitable to the convenience of the moment, hyper-texted to a virtual realm whose realities are supposed from data to hand but never known in and of themselves. But we forget this, repeatedly, and most particularly we forget it on every occasion that we establish an absolutist system on the basis of a projection from those momentarily persuasive, or even momentarily impressive, data. Critical endeavour, in all disciplines across the board, is almost always founded on this condition of willed amnesia. This condition requires amendment, and one, in particular, which embodies an ongoing practice which is more sustained and sustainable than a mere admission, as part of a course on critical theory, for example, that it is or that it may be so ${ }^{15}$.

\footnotetext{
13 The voice of the devil, in The Marriage of Heaven and Hell, quoted in Wilson, p. 174. I am indebted to Wilson's book for its reminder of Blake's central importance as a bridge between somatic (body) states, feeling, and intellect.

${ }^{14}$ On brain plasticity, see Doidge, Norman, The Brain That Changes Itself: Stories of Personal Triumph from the Frontiers of Brain Science. London: Penguin, 2007.

15 “As Hume formulated the problem (of establishing axiomatic truth by inductive-deductive reasoning) any attempt to validate induction is snared by one or another horn of a dilemma. It would have to be either an a priori argument or an empirical one. It cannot be the former, because all demonstrative reasoning depends on the avoidance of contradiction, and it is not a contradiction to argue that inductive reasoning could fail due to changes in the course of nature. Nor can the argument be
} 
Even from the point of view of such a formulation of the aetiology of perception, it is the case that a tendency (at minimum) towards a principle of coherence analogous to unaided seeing seems to underwrite aesthetic judgment. But, persuasive it might appear to be, this principle of coherence also has to be understood as the product of an imagining for which supporting data is subsequently found to be sufficient. With this realization, critical mind is born.

Returning to the examples already cited: In the matter of the beating of the heart (as in the matter of the origin of the universe), we are presented with two opposite and equally unsatisfactory explanations that "origin" is infinitely causally extended, or that it has a beginning. This being so, critical attention is in the first instance best confined to, but not justified by, a type of speculative empiricism which focuses on what seems obviously present for the moment of enquiry, and returns to presentness whenever the temptation to omniscience arises. In terms of the physical demonstration just cited: In the matter of vision, such speculation defines itself as a regulated limit upon response. In the matter of the beating of the heart, the somatic "algebra" for this pattern is a tightly organized sequence of electrical impulses. But in these examples, as in others, the "algebrae" of explanation contain an $\mathrm{X}$ term which requires filling out with a value ascribed by the perceiver-theorist, if a plausible version of objectivity is to be maintained, even temporarily ${ }^{16}$.

empirical, because it would be begging the question for induction to rely on itself for its justification”. Laurence Bonjour, $A$ Reconsideration of the Problem of Induction, Philosophical Topics 14:1, Spring, 1986, pp 93-124, retrieved from http://www.ditext.com/current/0001.html

I find sanction in the following passage from Hume of the notion that our experience of sight, and reflection on the heart's beating, and the uniformity of legal systems across cultures, suggest an underlying causal relation deducible from discrete apppearances, though it is not conclusively demonstrable from those appearances. It is this principle of cohesion which I sometimes call a "spectrum", and at others, a "matrix":

Although causation is the strongest associative relation, as well as the most important, our philosophical understanding of causation and the ideas closely related to it is seriously deficient: "There are no ideas, which occur in metaphysics, more obscure and uncertain, than those of power, force, energy or necessary connexion” (Enquiry Concerning Human Understanding, pp. 61-62). When we go beyond the single case to examine the background of experienced constant conjunctions of similar pairs of events, we find little to add, for "There is nothing in a number of instances, different from every single instance, which is supposed to be exactly similar” (EHU, p. 75). How can the mere repetition of conjunctions produce a connection? While there is indeed nothing added to our external senses by this exercise, something more permanent is laid down: "After a repetition of similar instances, the mind is carried by habit, upon the appearance of one event, to expect its usual attendant, and to believe that it will exist.” We feel this transition as an impression of reflection, or internal sensation, and it is this feeling of determination that is "the sentiment or impression from which we form the idea of power or necessary connexion. Nothing farther is in the case" (EHU, p. 75). Retrieved from http://www.plato.stanford. edu/entries/hume/

${ }^{16}$ (1) "The manner in which the I Ching tends to look upon reality seems to disfavour our causalistic procedures. The moment under actual observation appears to the ancient Chinese view more of a chance hit than a clearly defined result of concurring causal chain processes. The matter of interest seems to be the configuration formed by chance events in the moment of observation, and not at all the hypothetical reasons that seemingly account for the coincidence”. From C. G. Jung's Introduction to Richard Wilhelm's translation of the I Chine, quoted in Wilson, f/n, p. 146.

(2) Though the parallels between the way the visual is expressed in terms of a neurologically given matrix and the beating of a heart are useful demonstrations insofar as both processes occur within a clearly-defined range, there are also marked differences between them, one of which is that the rate of beating of the heart and the blood pressure range within which a body is able to function in good health is tightly regulated in order to support functional life to a degree that vision is not.

"The cardiovascular system is homeostatic in the sense that its various components, say heart rate and peripheral resistance, are regulated to maintain a constant blood pressure (the parameter in question) within fairly tight limits. Or the various biochemical and physiological processes that go into maintaining a constant blood $\mathrm{pH}$ of 7.4. There is usually also a loop feeding the parameter back to the system to help maintain this balance. 
In sum, we see and live momentarily, by the agency of processes whose regulation within narrowly-defined limits indicates a principle of cohesion reaching beyond whatever causal sequence is supported by those measurements of the moment brought to bear upon it. Also and equally, whatever explanation or explanatory system seems to be implied by the evidence to hand, its falling short of clinching empirical demonstration or theoretic closure will sooner or later become evident, at which point that explanation will itself have either to be modified, or abandoned.

When attention is turned from physiological processes to social behaviors, evidence of a similar hard-wired matrix is found in the universal acceptance of the expectations, responsibilities and graduations of punishment in legal systems, across cultures. The designs and projected outcomes of these systems, as well as the degree of submission given to them, are so similarly restricted as to imply a principle homologous with which ties visual perceptions to its neurological set. The most plausible explanation for this universal narrowness of expectation and responses, otherwise astonishing, given the range of possibilities excluded, is that, like physical vision, the tacitly, widely agreed ethics of jurisprudential practice are grounded in a spectrum of "proper" seeing. Eating people is widely acknowledged to be wrong, contacting the emergency services, if someone is seriously injured, appropriate ${ }^{17}$.

\section{The Mirror Neuron System: Ventromedial Prefrontal Cortex and the Consensual Spectrum}

The Mirror Neuron System in the orbito-frontal cortex and the ventromedial prefrontal cortex, and the (right) amygdala, with a number of other precisely located cell groups, is generally considered to be crucial in the development of empathy, though there are some dissenting voices ${ }^{18}$.

According to Antonio Damasio, it is the ventromedial prefrontal cortex which "provide(s) the substrate for learning an association between certain classes of complex situation on the one hand and the type of bio-regulatory state (including emotional states) usually associated with that class of situation in past individual

The eye in itself does not constitute a system. More problematically, sight is never regulated as an end-point parameter; the body does not really care nor can it tell how well one sees (Although the lack of retinal cell stimulation does risk their becoming dormant in the long term with ensuing blindness).

IOP (intra-ocular pressure), on the other hand, is strictly regulated-That is where homeostasis comes in. But the homeostatic control of IOP has a patchy effect on the quality of vision as a whole, as evidenced by the large numbers of people with perfectly normal IOP who are stricken with astigmatism, myopia, presbyopia and age-related macular degeneration. It is only in glaucoma that there is a direct relationship between the quality of sight and IOP... and hence a tenuous link with homeostasis to the extent that IOP affects vision in glaucoma. Tenuous nonetheless, because the feedback loop for IOP does not include eyesight; the end-point target is always IOP, not visual acuity. Personal communication, Dr. Leong Yan Hoi.

${ }^{17}$ Cannibalism offers a stern test for empathy theories of aesthetic response, which they can withstand by dividing the practice into consensual and non-consensual modes, designating the latter as murder, and gathering the former into practices directed, in the case of the devouring of an enemy, towards an incorporation of his virtues. Seen from this second perspective, it might be argued, cannibalism constitutes an ultimate act of empathy of a peculiarly unrefined sort.

${ }^{18}$ Trends in Cognitive Sciences, Vol. 11, No. 10, Letters (Casati and Pignocchi) and Letters Response (Gallese and Freedberg), ibid, p. 411.

"Moral judgment is like aesthetic judgment, writes Jonathan Haidt, a psychologist at the University of Virginia. 'When you see a painting, you usually know instantly and automatically whether you like it. If someone asks you to explain your judgment, you confabulate’”. Lehrer, Jonah, The Decisive Moment: How the Brain Makes Up Its Mind. Melbourne: Text Publishing, 2009, p. 166. 
experience" ${ }^{\text {} 19}$. That is to say, the ventromedial prefrontal cortex governs a learning association in balancing the emotion and judgment involved in a current event by relating these two factors to their appearance in past encounters of a similar sort. Also, significantly, "Decision-making does not arise from the orbito-frontal cortex alone, but from large scale systems”,20. In a manner of speaking, these activities occur in "islands” of cell groups in different brain regions, which coordinate in certain emotional, especially empathetic, responses, as though an invisible conductor had waved a baton over them. This may be taken as parallel to the principle of cohesion implied in the coordination of different sense impulses as a single visual event, or the underlying principle of governance implied in a diffuse electro-chemical activity such as the beating of the heart.

Damasio thinks that the ventromedial prefrontal cortex which provides the matrix for this principle of cohesion is itself sufficient explanation for this principle. But, as in the case of textual interpretation according to structuralist's principles, the question of origin is not resolved by a more precise specification of data. The matter of foundation, in a parallel with Gödel's theorem concerning any arithmetic series, always remains as an $\mathrm{X}$ which is both necessary and unresolvable. It may always be asked, as it must in this case: What is the initiating prompt and grounding principle, which provide continuity of impulse which turns the ventromedial prefrontal cortex persistently to its task? A similar paradoxical fork confronts the enquirer after foundational causes in contemplating the beating of heart, and the factual content of an aesthetic experience, as it does, as previously mentioned, in contemplating the origin of matter itself, no less. The choice between ultimately unsatisfactory alternatives, either an origin which is both specific and sufficient to its moment, or

\footnotetext{
${ }^{19}$ Decision-making and the Orbitofrontal Cortex, in Oxford Journals (Vol. 21, No. 6, June, 2011), Antoine B., Hanna D. and Antonio R. D., pp. 295-307. "The experience we acquire regarding a complex situation and its components-a certain configuration of actors and actions requiring a response; a set of response options; a set of immediate and long-term outcomes for each response option-is processed in sensory imagetic and motor terms and is then recorded in dispositional and categorized form. But because the experience of some of those components has been associated with emotional responses, which were triggered from cortical and sub-cortical sites that are dispositionally prepared to respond, it is proposed that "the ventromedial prefrontal cortex establishes a linkage between the disposition for a certain aspect of a situation (for instance, the long-term outcome for a type of response option), and the disposition for the type of emotion that in past experience has been associated with the situation” (My emphasis).

Because words, such as "images, neural patterns, representations, and maps" take on various connotations in different hands, their use is sometimes not as precise as it might seem.

Damasio uses “'images” as a synonym for mental images to which neural activity is analogous but with which it is not necessarily concurrent: "Mental images_are the mental constructs we normally experience in consciousness. Neural patterns or neural maps or maps are the neural_representation of the mental images” (Damasio, Feeling of What Happens: Body, Emotion and the Making of Consciousness. London: Heinemann, 1999, p. 317). Jean-Pierre Changeux considers the mental image as an autonomous and transient memory object, not requiring direct interaction with the environment (Changeux, Jean-Pierre, Neuronal Man: The Biology of Mind, Princeton, N. J.; Princeton University Press, 1997, L. Garey, Trans., p. 138. Retrieved from http://www. willcom/bio-consciousness/review/Mental\%20Image.htm). Scientific Understanding of Consciousness as an Emergent Property of Thalamocortical Activity.

However the term "images" is construed, the salient point for the present argument is the hiddenness of dispositional processes in comparison with topographical constructs (with mental images and cognitive rationalization of those images however these are construed, that is to say).

${ }^{20}$ Life Sciences and Medicine, Oxford Journals, Vol. 10, No. 3, Cerebral Cortex. Special Issue: The Mysterious Orbitofrontal Cortex. "Decision-Making and the Orbitofrontal Cortex", Antoine B., Hanna D. and Antonio D., pp. 295-310. (“The term 'dispositional is synonymous with implicit and non-topographically organized’”, Damasio), retrieved from http://www. cercor.oxfordjournals.org/ content/10/3/395.full

The germane point here concerns the apparent necessity of a principle of coordination which gathers discrete and diffuse regional brain events into a single response.
} 
one which is (apparently) infinitely regressive, is continually incumbent, and while a decision has to be made if pragmatically applicable explanation is to be achieved even as a temporary resting place, it should not be supposed that objectivity will accrue to the choice by reason of data "discovered" to support one's preference.

A similar pattern of a diffusion of impulses focused and "conducted" empathetically, and mistaken as objective representations of an external fact, occurs in our responses to literature. The authors turn next to this connection.

\section{Literature Review}

The link between empathy and aesthetic response is the clearest in literature, an important part of whose brief has always been the projection of readers beyond their affective habitude. There are many examples, some often cited, from Dickens' influence on social legislation in 19th century England, drawing a longer bow to the influence of the likes of Harper Lee and Harriet Beecher Stowe on Lyndon Johnson's civil rights legislation. But the really telling demonstration of this link is what happens when we next take up a novel, for example and begin to read it. As a rule, overwhelmingly so, we look for an empathetic connection and are disappointed, perhaps even taken aback, if it is lacking. Little inducement is required. Mere familiarity with a favoured version of a largely unconscious process of pre-perception is sufficient to confirm those meanings perceived as being most significant, or obvious. Neurological inscription comes with a patina of certitude.

For example, previous encounters with the film or novel The Hunchback of Notre Dame will dispose a reader's later responses to Frankenstein, novel or film ${ }^{21}$. From the other end of the spectrum, an unresponsiveness to James Joyce's (1922) Ulysses, especially if characterized by a blankness of the never-seen-the-like-before sort, is explicable by the want of a predisposition by which a reading of the book has previously been comfortably organized; a flat spot in the affective spectrum analogous to the gaps in a glaucoma sufferer's visual field. The project of disinterested decision-making would be considered from this perspective as an illusion of objectivity, much as the glaucoma patient supposes his visual field normal (up to a certain point of degradation) until his physician told him he was missing something.

\section{Psychological Implications of This Response}

In considering aesthetic responses in this way, we regard them as though from a distance sufficient to allow us to notice how much we are invisibly implicated in our predisposed choices. It is as though the critic-observer adopting such a perspective were looking into a text and through that into the life beyond as a construct whose representations are consciously acknowledged to be nothing more (but also nothing less) than homologies making modest, controllable, demands on absolute credulity ${ }^{22}$. The "set" and feeling of this sort of reflection are otherwise than the type of self-reflection advocated by Husserl whose observation of the essentially intentional nature of perception requires an observer who is in some manner transcendent to his point of observation and simultaneously able to dissolve into its moment. Different, too, from the self-reflection engrafted intermittently at decisive moments of an enquiry recommended in Pierre Bourdieu's "sociology of

\footnotetext{
${ }^{21}$ And in agreement with J-P. Changeux's view that "The nervous system is active rather than reactive, and that interaction with the environment results in the selection of preexisting internal representations”. Changeux, J-P., Neuronal Man: The Biology of Mind. (L. Garey, Trans.). Princeton, N. J.; Princeton University Press, 1997, p. 138.

22 “As the Italian philosopher Giambattista Vico (1744-1961[sic]) remarked, we cannot reconstruct the past exactly as it was, because we cannot avoid framing and understanding our recollections in terms of the concepts we have at present”. Glasenfeld, 2.
} 
sociology,23.

Situated philosophically, the critical cast of mind is Lockean insofar as it rests upon a grounding of observation in "ideas... such as the mind gets by reflection upon its own operations within itself", though quite other than Locke's sensation falling upon a blank slate + reflection model of consciousness, since the currently canvassed mode of empathetic aesthetic response does posit a substrate of neurological activity which is anything but "blank" ${ }^{24}$. Essentially, what is proposed is continual unrelenting re-establishment of the critical habit of catching a judgment at the point of one's joining with the observation of its operations, and to perceive such an activity in terms of what might be glimpsed of pre-established connections ${ }^{25}$.

There is perhaps no better reference for the crucial difference in the mind's contradictory inclination to mistake as natural law the product of its reflection and simultaneously to admit the tenuousness of its decisions than taking note of a difficulty inherent in Locke's model, in which an image of consciousness, which seemed balanced between the two parts of that description - the mind generating pictures of reality (solely) from reflections upon its operations, and the mind as blank slate-is established as an irreducible dichotomy by Locke's philosophic preference for as long as we see the matter with a Lockean eye; the specific against which is, to view the Locke's mind map as the consequence of a biochemical "set" grounded in auto-persuasive and neuro-physiological processes favored by that philosopher but having no general purchase on the reality of mind and its relation to the object world.

We have been proposing the universality of an empathetic-aesthetic connection as evidence of an underlying disposition, especially as this declares itself in literary works, and as indicated in the operation within the circumscribed parameters of human systems of jurisprudence.

The view of the aetiology of aesthetic response proposed here resists "poverty of stimulus" models ${ }^{26}$ of the sort proposed by theorists of mind influenced by the work of James. J. Gibson in their concept of a "subtle,

\footnotetext{
${ }^{23}$ See Pierre Bourdieu, An Invitation to Reflexive Sociology. Chicago; University of Chicago Press, 1992.

24 “The myth that Locke's empiricism held all knowledge to be derived directly from the senses was greatly reinforced by misunderstanding of his use of the term 'experience'. For him, this included not only the acquisition of sense ideas but also their retention and subsequent elaboration by means of reflection and abstraction”. Glasenfield, 33.

${ }^{25}$ It may be that David H.’s proposal of a criterion of contiguity which inscribes connections which come to seem natural provides a basis for a connection of empathy and aesthetic responses along evolutionary lines. As the organism discovers that empathy helps the survival of the group, empathy is neurologically inscribed as a normal part of the brain-state 'equipment-is "naturalized", so to speak. Subsequently, this faculty, having proven itself pragmatically useful, comes to be recommended, then admired. Subtler consent comes in time to be invited by means, for example, of the sophisticated figures employed in paintings, print, and in dramatic enactment. In this view, works of art appear as undeclared and de-dogmatized refinements of an ethical imperative, whether or not that imperative is acknowledged. See David H., An Enquiry Concerning Human Understanding. London. Millar, 1742, Essay 111.

${ }^{26}$ An argument for an ethical-pragmatic aspect of aesthetic response:

Peter Rickman (Having Trouble with Kant, Philosophy Now, 2011, September/October, p. 12), commenting on Kupperman’s A Messy Derivation of the Categorical Imperative, writes, "The commonsense view that there are moral imperatives which are not purely subjective and can be reasonably discussed presupposes a rational grounding for those imperatives. Knowledge of the facts, although indispensable, are (sic) therefore not enough, and feelings cannot provide a reliable basis, for they are subjective and may even change within a person through changing circumstances”.

Though Rickman is obviously right to say that feelings change at the prompting of context, there is I suggest a disposition to feel which is constant and which "combs" disparate feelings into alignment with the mother grain from which lesser feelings or feelings apparently inimical to it take a fainter imprint, and this is the impulse to empathy. Distaste for the other, for instance, or even outright loathing, signal their "out of true" nature by arousing unspecified misgiving in the beholder (sometimes, too grandly or readily called "conscience"). With Kant, I consider this to be a pre-inscribed and indelible ethical imperative, though not one based, in the first instance, as he supposes, on reason, but rather on this fundamental impulse to empathize. The origin of this impulse itself might however be considered to have been instituted (and continually to be reinstituted) as a pragmatic acknowledgement that the extension of empathy is conducive to maximizing the likelihood of individual and communal survival. See footnote 25 to this text.
} 
unbounded, permanent stimulus (of) information" in which the visual system is able to detect and explore accurately, as it does cognitive theories insofar as their picture of sensations "enriched" by a mental model rests upon a flexible realism which in the view taken here is a refinement of the naïve realism assumed by "stimulus information" models ${ }^{27}$. It defers to cognitivism to the extent of acknowledging the encompassing importance of point of view, embraced here in the janus-faced term "pre-disposition" (facing inwards towards deep structure aspects of mentation, outward to invitations to such modification invited by contextual prompts), but departs from the emphasis given to computational aspects of the image of mind to which theories of cognitive psychology are inclined. Ulric Neiser's criticism of Donald Broadbent for taking "cognition as a passive rather than a constructive process" makes the general point from within the cognitive psychology camp that we should wish to draw ${ }^{28}$. Such emphasis on an essentially digitalized model of perception seems not to allow sufficiently for one of the most consistently striking characteristics of aesthetic response, whatever the parameters in which it is rendered, namely, its fluidity or "slipperiness". Indeed, it might be said that is its scientistic bias which does not easily comprehend the fluent complexity of artistic "appreciation" which highlights an insufficiency of cognitive approaches in general ${ }^{29}$. Even cognitivism, with its relative deference to inner states in comparison to earlier cognitive theories, preferences economy of explanation to a degree offering an open sesame to reductionist descriptions of consciousness ${ }^{30}$.

\footnotetext{
27 "Flexible naturalism" is an application and extension of the idea of a flexible realism that has been developed by Peter Hare. In a discussion of the relationship between photographs and epistemic standards Hare says that a flexible realism "adjusts epistemic standards to the context and warrants assertions about the world accordingly". The flexibility relation obtains between justificatory standards and areas of inquiry where standards are free to conform to the particular needs of any context in which inquiry takes place. As such, flexible realism is a form of epistemic contextualism. However, Hare pairs this contextualism with a theory of epistemic virtue and, as such, is far more robust that traditional versions of epistemic contextualism”. Toward a Flexible Naturalism, 2008, SAAP Discussion Paper Submission, retrieved from http://www.philosophy.uncc.edu/mleldrid/SAAP/MSU/ DP08G.html (My emphasis. See Hare, 2007).

Given that such "justificatory standards" remain to be proven as "standards" after the invocation of context is offered as a grounding criterion of their objectivity, I cannot think of this project as anything more than an aggrandisement of naïve realism. The proposed "epistemic" virtue seems to add a moral aspect to perception and judgment which clouds the veracity issue it is imported to clarify.

28 "I am more sceptical than Broadbent about the value of information measurement... He argues that cognitive mechanisms must have a finite informational capacity—in terms of bits per second—and that filtering mechanisms are needed if that capacity is not to be overloaded. This is surely true in some sense, but it does not help us to understand the mechanism in question (My emphasis). Also: “Broadbent's filter' theory may mean that lack of attention can prevent stimuli from entering echoic memory”. Neiser, pp. 208, 177.

From the present point of view, Neiser locates a fundamental, all but automatic, error of structuralisms, namely, so close an engagement with the simplifications of explanation invited by a selection of data that questions of causal connection, and of origins, are overlooked. As a variation of this oversight, in the second quotation from Neiser, the criticism of Broadbent's filter' theory, the meaning of the word "attention" in that sentence has to be at least provisionally decided before enquiry finds direction. But the word "attention" is not often pursued, let alone decided, in cognitive psychology. Rather, it tends to be assumed to be single to the occasion in a constructed, "normal", subject, and constant unless interrupted. See pp. 3-4 of this paper, on the American New Critics and the Chicago School of Literary Criticism.

${ }^{29}$ A viewer might feel differently about, and therefore judge differently, a film on re-viewing it six months after his first encounter with it, and differently again reviewing it after six years and 16 and 60; these differences might be subtle, or not, but they will be present, and not only characteristic of his reception of a work of art, but crucial to that reception.

30 "Although Blade Runner holds a brief for renegade cyborgs as de facto humans who claim at least parity with their creators and masters, the implicit argument is neither decisive nor finally persuasive. At best, the resolutions — commonly interpreted as Roy's compassion and Rachael's love-function as undecidable, the Socratic aporia brought to its logical (or paralogical) extreme in postmodern art”. Clifford Hallam, The Indeterminate Sign in Ridley Scott's Blade Runner, Director's Cut, Philological Papers, Vol. 54, West Virginia University, 2011, p. 120.
} 
The position outlined here is closer to a constructivist ${ }^{31}$ model of the sort proposed by Ernst Glasenfeld with the important difference that the pre-existing mental structures that arrange and establish such information are perceived as empathy-based rather than, as they seem to be in the constructivist model, affect describable by means of a form of conceptual-semantic algorithm, a commitment to the proposition, in the constructivist model, that "Words stand for concepts and definitions should specify the operations one has to carry out to build up the concept" ${ }^{\text {32 }}$.

The difficulty of the division noted in Locke arises from supposing natural what has been naturalized, which is not to overlook the fact that the present account is inevitably to some degree such a rationalization, with, the author thinks, this advance: The current suggestion is that critical enquiry in general should be engaged as far as possible in a state of mind prepared to make use of whatever explanations, plural, seem to render that moment intelligible, without commitment to those explanations as a summary point which acts as a semi-visible constraint, or even a terminus, to further enquiry. This would be an application to the perception and critique of data across disciplines which find company in F. Scott Fitzgerald's definition of a "first-rate" intelligence as "The ability to hold two opposed ideas in the mind at the same time, and still retaining the ability to function". Much to be avoided is any tendency towards precipitous decisiveness and an embrace of totalizing statement for the sake of ameliorating uncertainty, given that any close-of-play statement whatever,

\footnotetext{
31 "From all this, with the help of Piaget's theory of cognitive development, radical constructivism formulated its fundamental principles: 1 . Knowledge is not passively received either through the senses or by way of communication. Knowledge is actively built up by the cognizing subject. 2 . The function of cognition is adaptive, in the biological sense of the term, tending towards fit or viability. Cognition serves the subject's organization of the experiential world, not the discovery of an objective ontological enquiry”. Glasenfeld, 50-1.

As to the more important critiques of constructivism, for instance, that its relativism requires that "constructivism itself would be false in (another) social formation”, see Glasenfeld's refutation of this (pp. 87-88), and my discussion of a similar version of this oft-produced apparent contradiction in relation to anti anti-foundationalist arguments in Reading Literature After Deconstruction, pp. 139-143.

There is also the objection brought against constructivism that if the concepts of two different social formations (are) supposed to be incommensurate it would be logically impossible to make decisive judgements about them from a third point of view which must present itself as superior to the two social formations upon which it deliberates in the act of judging.

As a practical matter, this difficulty disappears if one simply behaves conversationally "in good faith" as though communication were secure, until evidence to the contrary presents itself. This, while remaining alert to the possibility of the presentation of such evidence. The difference between this version of a "good faith" approach and that advocated by Gadamer (see his conversation with Derrida in Michelfelder and Palmer) is that Gadamer seems to expect that the simple adoption of a co-operative principle in itself will eliminate or override misunderstanding. The approach suggested here is, rather, one of "operate according to an expectation of the best while keeping a sharp eye open for the worst"-good faith underpinned by scepticism, or realism, it might be claimed. This is consonant with the position Glasenfeld takes. See especially his discussion of Saussure, pp. 46-48.

${ }^{32}$ Glasenfeld, 7. Though against reductive versions of Percy Bridgeman's operationalism which have, in Glasenfeld's view, been fashioned by behaviourists, the emphasis of Glasenfeld's constructivism on conceptualization-even while emphasizing with beautiful economy the irreducible difference of world view consequent on subjective variation—still tends to miss the point I wish to make that such differences are generated by, and grounded in, a commonality of feeling and are not so far removed from each other as a focus on conceptualization would suggest. An example Glasenfeld cites (p. 8) to illustrate a conceptual difference which is linguistically enforced, seems without his marking the fact to confirm the overriding importance of the sort of affective communality, and communion, I have been indicating. I quote this instance in full:

"Of course, there is a great deal of practical overlap because... differences are often very subtle and seem irrelevant in ordinary experiential situations. What we call communication works well enough whether an English girl says 'I like that boy', or an Italian 'questo ragazzo mi place'-It does not seem to matter that the one expression assigns the active role to the girl, the other to the boy. But it does show that the speakers' worlds are conceptualized differently” (p. 8).

The reason it does not matter is surely that affect-feeling-dominates concept. Glasenfeld does not allow this because he is too focused on the importance of conceptualization (and in this passage, the absolute impossibility of "accurate translation", a stance with which I agree), to acknowledge something implicit in the very example he has chosen. Amor, rather than ratiocination, vincit omnia.
} 
in the view presented here, will be precipitous ${ }^{33}$.

\section{Empathy, Melancholy, and Lyotard}

A possible objection to the approach outlined here is that it ties aesthetic effect too closely on an empathetic response without allowing sufficiently for exceptions. What is our enjoyment of the macabre and the ghoulish in literature? What is melancholy? What, perhaps most challengingly, is the sado-masochistic imperative ? $^{34}$

Aside from the fact that it is possible to keep considerable empathy for one's melancholy - the rich tradition of the "accursed poet" (poète maudit) is testimony — which can modulate into appreciation even of one's failure to achieve happiness, an important part of the ventromedial sector's task is to maintain neuro-psychological equilibrium, and this might conceivably encompass an aesthetic appreciation which balances an experience of the dreadful with the pleasure of marking one's distance from embodiments of this condition in a novel or drama. Such a response might fairly be considered consonant with the Coleridge/I. A. Richards' project for literature as an instrument for a balancing and reconciliation "of opposite or discordant qualities" 35 .

Similar exceptions which might be cited, for example, literatures flung at the philistine to excite his distress, not an obvious indication of empathy, might be met by observing that unsettling people who you do not like can also tend pleasingly to moderate an unexpressed conflict, even at the initial basic, some might say base, level of shouting "Merde!" to an audience brought out of their houses in the expectation of having their sensibilities refined $^{36}$. The additional pleasure of hearing your "avant-garde" friends declaring what good art you have made of your antagonism might season the occasion. Here, the story to oneself might be one of indignation raised heroically to the level of an empathy for the better selves one was trying to shock one's audience into assuming; or, more tenuously, elevated from self-pity to sympathy for the sacrifice of position almost certain to result from offending the powerful. To the conservatively inclined, on the other hand, such apologia will appear as little more than variations on the terrible twos theory of rebellion, in which the bourgeois is set about as the next best thing to assault the knees of the father.

But what melancholy re-presented as delight? That seems harder to gather into a theory of kindly inclination. "This sorrow is heavenly", Othello says. Unhappily for a theory of empathy, he says that just before he kills Desdemona. Melancholy seems on such occasions to run a little too readily to extremes of self-justification to provide a convincing candidate for sublimation.

\footnotetext{
${ }^{33}$ Principles of Multiple Explanation and Delay. The critical mind set suggested here can be considered as a composite of Fitzgerald's description, Epicurus' Principle of Multiple Explanations (see Robert Lumsden, Taste and Judgment, retrieved from http://www.inter-disciplinary.net/wp-content/uploads/2011/08/lumsdenbpaper.pdf), and Coleridge's description of a superior critical approach as one which avoids "an irritable reaching after fact and reason". Also, "another important tenet of constructivist theory is that there is no single valid methodology but rather a diversity of useful methods" (Glasenfeld, pp. 109-110). "The test of anyone's account that purports to interpret direct experience or the writings of another, must be whether or not this account brings forth in the reader a network of conceptualizations and reflective thought that he or she finds coherent and useful”.

${ }^{34}$ This nexus of impulses need not prove as troublesome to an empathy theory as it might seem at first sight. Reading "love" as an epitome of empathy, masochism can be taken as a reaction to the absence or loss of love-libido turned against oneself in anger and disappointment — and sadism a punishment of the other for love felt to be unfairly withheld. In both cases, a heightened "version" of empathy stands as the (displaced) principle informing an impulse, and its consequent actions, even those which seem contrary to it. (See Sigmund Freud, Three Essays on the Theory of Sexuality).

${ }^{35}$ Samuel Taylor Coleridge, Biographia Literaria, Chapter 4.

${ }^{36}$ De-familiarization, too, can be kept within the empathetic-aesthetic orbit by taking it as a technique to alienate the reader temporarily to effect a more complete "joining with" the text.
} 
More plausibly, perhaps, defence of an empathy theory of aesthetic response might point to certain bridges between the self-concern implicit in melancholy and attempts to extend that isolated sense of self to others. Exponents of the Blues, for instance, not unreasonably, given the enduring, widespread, cross-cultural popularity of the music, assume universal resonance for a local, individual suffering.

A better reason for suspecting such attempts to bring all instances of melancholy under the umbrella of empathy rests with an overtone of effortfulness in such attempts, a surplus of invention of the sort on display in the previous four paragraphs, which might feel on reading or re-reading, depending on the pre-disposition the reader brings to them, as much part of an attempt to avoid the possibility of counter-argument as a convinced conjoining with one's subject. This is more seriously so when an attempt is made to "transform" melancholy, as Jean-François Lyotard does in his meditation on the sublime, to which the author turns, in conclusion.

Lyotard thinks that melancholy marks a lesser order of the sublime than "novatio", which he conceives to be "an intrinsic combination of pleasure and pain". According to Lyotard, in this second, higher, experience of the sublime, critical thinking discovers its destiny in the movement towards an exultant acceptance of its limitations. In a sense, critical thinking auto-sublimes by thinking itself part-way out of its customary "modus" "operandi”. But if critical mind at its highest is other than it has been in bringing us to the point where we are able to glimpse possibilities which lie beyond it, how might we convey this good news in a form which will not damage the vehicle of transmission to those still using and therefore to a degree embedded in the language which is to be superceded? Is it possible to recommend a critical language for its sublimatory potential, while critiquing its deficiencies, "qua" discourse?

"Novatio" from the current perspective appears, not as the consequence of a discursively achieved transformation, but as an aspiration pushing back against the strictures involved in thinking about limitation, and simultaneously a pressing down into the unconscious of a fundamental anomie against which we have traditionally brought to bear, among other measures, the same critical intelligence Lyotard wants to modify ${ }^{37}$. To the mordant dualist, the better course seems to remain as happy as possible with the Blues, whose music secures its lines of transmission in telling longingly of a heaven yet to be attained, rather than attempting to raise the pitiful in an epiphenomenal projection which is somehow rendered superior to its usual appearances in hovering dependently above them.

\section{References}

Bourdieu, P. (1984). Distinction a social critique of the judgment of taste. (R. Nice, Trans.). London: Routledge \& Kegan Paul. Bourdieu, P. (1992). An invitation to reflexive sociology. Chicago: University of Chicago Press.

Broadbent, D. R. (1958). Perception and communication. London: Pergamon Press.

Changeux, J. P. (1997.). Neuronal man: The biology of mind. (L. Garey, Trans.). Princeton: N. J. Princeton University Press.

Doidge, N. (2007). The brain that changes itself: Stories of personal triumph from the frontiers of brain science. London: Penguin.

Eco, Umberto. (1980). Two problems in textual interpretation. Poetics Today, 2(1a), 145-161.

\footnotetext{
37 "Sublime feeling is analysed as a double defiance. Imagination at the limits of what it can present does violence to itself in order to present that it can no longer present. Reason, for its part, seeks, unreasonably, to violate the interdict it imposes on itself and which is strictly critical, the interdict that prohibits it from finding objects corresponding to its concepts in sensible intuition. In these two aspects, thinking defies its own finitude, as if fascinated by its own excessivesness". Answering the Question "What Is Postmodernism?”, in The Postmodern Condition: A Report on Knowledge. (G. Bennington \& B. Massumi, Trans.). Minnesota: University of Minnesota Press, 1984, p. 79.
} 
Freud, S. (1949). Three essays on the theory of sexuality. (J. Strachey, Trans.). London: Imago.

Gibson, J. J. (1950). The perception of the visual world. Boston: Houghton Mifflin.

Glasenfeld, Ernst von. (1995). Radical constructivism: A way of knowing and learning. London, Washington, D. C.: The Falmer Press.

Greimas, A. J. (1983). Structural semantics: An attempt at a method. (D. Mc. Dowel, R. Schleifer, \& A. Velie, Trans.). Nebraska: University of Nebraska Press.

Hare, P. H. (2007). Photography, popular epistemology, flexible realism and holistic pragmatism. In W. Irwin, \& J. E. G. Jorge (Eds.), Philosophy and the interpretation of Pop culture. Lanham: Rowman \& Littlefield.

Hume, David. (1999). An enquiry concerning human understanding. In T. L. Beauchamp (Ed.). Oxford, New York: Oxford University Press.

Iser, W. (2006). How to do theory. Oxford. Blackwell Publishing.

Lehrer, J. (2009). The decisive moment: How the brain makes up its mind. Melbourne: Text Publishing.

Lyotard, J. F. (1994). Lessons on the analytic sublime. (E. Rottenberg, Trans.). Stanford: Stanford University Press.

Lyotard, J. F. (1984). Answering the question: “What is postmodernism?”. In The postmodern condition: A report on knowledge.

(G. Bennington \& B. Massumi, Trans.). Minneapolis: University of Minnesota Press.

Lyotard, J. F. (1988). The different: phrases in dispute. Minneapolis: University of Minneapolis Press.

Lumsden, R. (2009). Reading literature after deconstruction. Amherst: Cambria Press.

Metzinger, T. (Ed.). (1995). Conscious Experience. Schoningh: Imprint Academic.

Michelfelder, D. P., \& Palmer, R. E. (1989). Dialogue and deconstruction: The Gadamer-Derrida encounter. Albany: State University of New York Press,

Neiser, U. (1967). Cognitive psychology. New York: Meredith Publishing Company.

Nijinsky, V. (1937). Diary of Vaslav Nijinsky. London: Gollancz,

Propp, V. I. (1958). Morphology of the folktale. (L. Scott, Trans.). Austin: University of Texas Press.

Wilson, C. (1970). The outsider (3rd ed.). London: Pan Books. 